\title{
The effect of education, income inequality and merit on inequality acceptance $^{1}$
}

Abigail Barr², Luis Miller³

20 April 2020

\begin{abstract}
A large number of observational and experimental studies have explored the determinants of individual preferences for redistribution. In general, inequalities are more likely to be accepted by people of higher socioeconomic status, in richer societies and when inequalities are perceived as justifiable owing to differences in productivity. Almas et al. (2019) show that in a relatively unequal society (the United States), the highly educated accept inequality significantly more than the less educated, whereas, in a relatively equal society (Norway), the less educated accept inequality more, but not significantly more, than the highly educated. Here, we replicate this finding using data from experiments conducted in four locations across three countries all distinct from the ones studied by Almas et al. However, a closer look at the data indicates that the origin of the interaction effect varies depending on which societies one compares. Data for Norway and the United States indicate that meritocratic values among the highly educated are less prevalent in more equal societies and that this is the driver of the triple interaction effect. In contrast, in our data the interaction effects have multiple drivers.
\end{abstract}

Keywords: education | lab-in-the-field experiments | inequality | redistribution

\footnotetext{
${ }^{1}$ Luis Miller acknowledges support from the Spanish Ministry of Economy and Competitiveness (Grant ECO2015-67105-R).

${ }^{2}$ School of Economics, University of Nottingham.

3 Spanish National Research Council (IPP-CSIC), C/ Albasanz 26, 28037 Madrid, Spain. To whom correspondence should be addressed: E-mail: luis.miller@csic.es.
} 
Why is economic inequality regarded as acceptable in some societies and not in others? In a recent paper, Almas, Cappelen, and Tungodden (2019) (hereafter “ACT") report a finding of potentially great importance for the study of inequality acceptance -i.e., the extent to which economic inequalities are considered fair or acceptable. In a relatively unequal society (the United States), the highly educated accept inequality significantly more than the less educated, whereas, in a relatively equal society (Norway), the less educated accept inequality more, but not significantly more, than the highly educated. Further, this interaction between (individual) educational level and (societal) income inequality occurs only when the inequality is owing to a difference in productivity, i.e., it is a triple interaction effect involving a spectator's level of education, the source of the inequality under scrutiny, and the overall level of inequality in the spectator's society. ${ }^{4}$ Unfortunately, this finding is not the main focus of their study and it is not interpreted or discussed in the article.

This result is important because it offers a direct empirical test of the joint effect of three sets of determinants of inequality acceptance: individual characteristics, societal economic inequality, and knowledge about the origin of inequality. When it comes to individual determinants, the so-called 'self-interest' approach — the upper classes and people of higher socioeconomic status opposing equalisation-is supported by observational and experimental studies. In sociology, this has been shown using longitudinal and cross-national panel surveys (Owens and Pedulla, 2014; Fernandez and Jaime-Castillo, 2018). In political science, Margalit $(2013 ; 2019)$ finds that the experience of economic hardship has a positive effect on stated preferences for redistribution. In economics, Alesina and Giuliano (2010) report a robust correlation between socioeconomic status and attitudes towards redistribution and equalisation.

The overwhelming support for the individual self-interest hypothesis has no counterpart in the study of the societal determinants of inequality acceptance. By societal determinants, we refer to the effects of macro-level variables (e.g., income inequality) on individual values and preferences. Although previous studies have failed to establish a clear correlation between existing economic inequality and average levels of inequality acceptance (Alesina and Giuliano 2019), there is some evidence-limited to a handful of countries-suggesting that in more unequal contexts people would consider inequalities more acceptable (Castillo 2011; Sands 2017; Almås et al. 2019).

\footnotetext{
${ }^{4}$ In this paper, following Konow (2005), we use the labels spectator and stakeholder.
} 
Finally, in economic experiments one can manipulate and study the effect of the origin or source of inequality on inequality acceptance. Participants in economic experiments are more likely to accept inequalities when: (1) they are more educated, they have a higher economic status or they are not unemployed (see, for example, Jakiela, Miguel and te Velde, 2014; Barr et al. 2015; Barr et al., 2016;); (2) they are from richer countries (see, for example, Cappelen et al., 2013; Jakiela, 2015); and (3) when the source of inequalities is a difference in effort or productivity (see, for example, Konow, 2000; Cherry, Frykblom, and Shogren, 2002; Frohlich, Oppenheimer, and Kurki, 2004; Barr et al. 2015; Almas et al., 2019).

Here, using data from lab-in-the-field experiments, we show that ACT's finding replicates $^{5}$ when we compare Bilbao (a highly equal society) with Oxford, Córdoba (both relatively unequal societies), and Cape Town (a highly unequal society). However, we also show that the drivers of the triple interaction effect vary depending on which societies are compared.

\section{Method}

We make use of the data generated by Barr et al. (2015) and Barr et al. (2016) who conducted the same experiment in each of four locations: Oxford (United Kingdom), Cape Town (South Africa), Bilbao and Cordoba (Spain). ${ }^{6}$ In the experiment, participants first engaged in a realeffort task and then played four-person random dictator games (4PDGs). The real-effort tasks were easy-to-understand, manual and required no skills. In the 4PDG, a tray divided into four quadrants, with each quadrant corresponding to one of the four players, was handed to each participant. Each participant knew which of the quadrants on the tray corresponded to him- or herself. The initial endowments of each of the four were indicated by black counters placed in each quadrant. The distribution of the four initial endowment values was unequal. Participants were then told they could redistribute the counters however they wanted. Once everyone had finished, the final allocations proposed by one of the four, randomly selected, were used to determine the final payoffs for all four players. The participants did not know who they were playing with and their redistribution decisions were made in private and kept anonymous.

\footnotetext{
${ }^{5}$ Strictly speaking, we do not conduct a pure replication of ACT's study, but a new test of the triple interaction finding reported in their study. The main methodological differences between the two studies will be discussed in the Method section.

${ }^{6}$ This is the first time that all the data from the two projects has been pooled. Additional details on experimental samples and procedures can be found in Barr et al. (2015), Barr et al. (2016) and Demel et al. (2019). The original aim of these studies was to test the effect of socio-economic and employment status on the acknowledgement of earned entitlement.
} 
There were two treatments. In the earned treatment, participants' initial endowments in the 4PDG were determined by their within session performance rank in the real-effort task. In the random treatment, the initial endowments in the 4PDG were randomly assigned. The initial endowment distribution was held constant across the two treatments.

Both ACT and Barr et al. $(2015 ; 2016)$ focus on how redistributive decisions vary depending on whether initial inequality is owing to productivity or luck. However, there are several important differences between the two experiments. First, the Barr et al. $(2015 ; 2016)$ participant sample is not representative, but is large $(n=626)$ and heterogeneous in terms of sex, age, economic status and education: $52 \%$ women; median age $=29(\mathrm{p} 10=24, \mathrm{p} 90=45) ; 36 \%$ report being low income or poor; and $44 \%$ have post-secondary education. Second, ACT conduct an online experiment, while Barr et al (2015, 2016) conduct lab-in-the-field experiments. Third, in ACT the decision-maker is an unincentivized spectator who redistributes payoffs across two other agents, while in Barr et al. $(2015 ; 2016)$ the decision-maker is an incentivized random stakeholder who redistributes resources across four participants, one of whom is him- herself. Given these differences, our reanalysis of the Barr et al $(2015,2016)$ data should be viewed, not as a pure replication, but as a check of the robustness of ACT's findings.

For the Barr et al. $(2015 ; 2016)$ data, we use an adaptation of ACT's method to construct a variable Implemented inequality, that captures the inequality across final payoffs assigned to the other three stakeholders in the 4PDG by dictator $i .^{7}$ Formally:

$$
\text { Implemented inequality }_{i}=\frac{\left|y_{j}-y_{k}\right|+\left|y_{j}-y_{l}\right|+\left|y_{l}-y_{k}\right|}{2\left(y_{j}+y_{k}+y_{l}\right)} \in[0,1],
$$

where: $y_{j}, y_{k}$ and $y_{l}$ are the final payoffs that $i$ chooses for group members $j, k$ and $l$ respectively; the numerator is the sum of bilateral final payoff differences across all stakeholders, excluding the dictator; and the denominator normalizes the measure to lie between zero (all stakeholders, excluding the dictator, earn the same amount) and one (one stakeholder receives a positive final payoff, the other two receive zero). ${ }^{8}$

\footnotetext{
${ }^{7}$ We exclude the dictator's final payoff from the calculation, thereby, focusing attention on the inequality that the dictator implements across the other three stakeholders. We follow the econometric approach introduced in Barr et al. (2015) and Barr et al. (2016).

${ }^{8}$ Both ACT's method and our adaptation of it generate a useful measure of implemented inequality, given the research question, only if no or very few participants invert the distribution -i.e., create greater inequality to the benefit of unlucky or less productive participants. ACT's figure 2 indicates that very few of their participants did this. In the Barr et al. (2015; 2016) experiments, possibly because initial inequality, rather than being set to 1 , ranged between 0.11 and 0.60 , a larger share of around $5 \%$ inverted the distribution. We exclude the data points for these participants from the analysis presented below. Alternative approaches to accommodating such
} 
Our three independent variables of specific interest are highly educated, equal to one for those who completed the equivalent of high school in their country, merit, equal to one for those under the experimental treatment where productivity ranking determined initial endowments in the 4PDG, and, in place of ACT's indicator for experimental participants in Norway, the more equitable of their two societies, we use an indicator for experimental participants in Bilbao, the most equitable of our four societies. The Gini index for disposable incomes in Bilbao and Norway are remarkably close (slightly above 0.25 ), while the Gini indexes for Córdoba and Oxford are similar to the index for the United States (close to 0.4), and the Gini index for Cape Town is markedly higher (above 0.6).

\section{Results}

Figure 1 graphs the average Implemented inequality for the dictators with each level of education, under each experimental treatment and within each society. ${ }^{9}$ It is constructed in the same way as the panels focusing on education in ACT's Figure 5. We observe the following: (1) A difference in productivity instead of luck causes a large expected but not always significant increase in inequality acceptance across the locations (Bilbao: $p=0.004$; Oxford: $p$ $=0.092$; Córdoba: $p<0.001$; Cape Town: $p=0.167$ ) (see Table 1 for details relating to $\mathrm{p}$ values); (2) highly educated dictators respond more strongly than less educated dictators to the introduction of a difference in productivity in the most unequal OECD location (Oxford: $p=$ 0.047) (see Table 1); (3) the pairwise differences between Bilbao, on the one hand, and Oxford, Córdoba and Cape Town, on the other, in the interaction between merit and highly educated are all negative but variably significant (Bilbao vs. Oxford: $p=0.011$; Bilbao vs. Córdoba: $p=$ 0.096; Bilbao vs. Cape Town: $p=0.075$ ) (see Table 2 for details relating to $\mathrm{p}$-values, columns 1-3); and (4) when we pool the data from the three most unequal locations (Oxford, Córdoba

inversions, e.g., multiplying the measure by -1 when the distribution in inverted, yield results similar to the ones we present below.

${ }^{9}$ The mean levels of Implemented inequality are much lower for every defined sub-sample in our data compared to ACT's. This may be because, in ACT initial inequality was 1, while in Barr et al. $(2015 ; 2016)$ it ranged between 0.11 and 0.60 . 
and Cape Town), the triple interaction between merit, highly educated and the indicator for Bilbao is statistically significant $(p=0.024)$ (see Table 2, column 4). ${ }^{1011}$

FIG. 1.-Implemented inequality by defined sub-samples

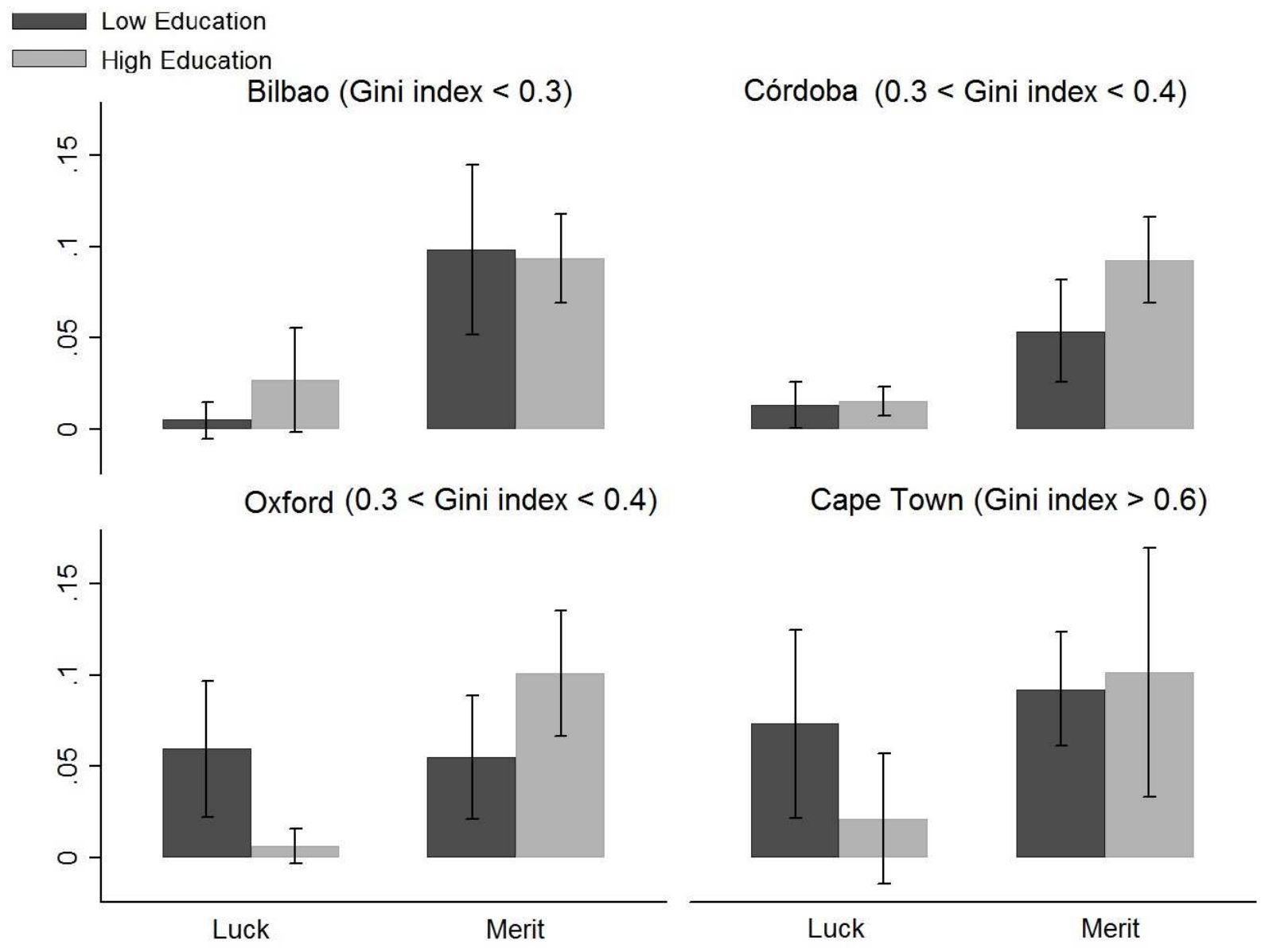

Note: The figure shows the average level of implemented inequality for each subgroup in the two treatments. The whiskers indicate standard errors.

When we focus on the three OECD locations, this summary of results appears broadly consistent with ACT. However, when we look carefully at the regressions in Table 2 and at Figure 1, we see that especially Cape Town but also Oxford appear different to Bilbao and Córdoba. Further still, when we compare Figure 1 to the middle panel of ACT's Figure 5, we see that, while the graphs for Bilbao and Córdoba are each qualitatively similar to those for

\footnotetext{
10 The triple interaction between education, merit and location in ACT's main analysis (Table 4, column "Education") yields a p-value of 0.075 . However, in their appendix, they report that this result is not robust to multiple testing adjustments. Multiple testing is relevant in their case because they test two experimental treatment effects (merit and efficiency) and three dimensions (political attitudes, education and gender). We use the Benjamini-Hochberg's (1995) false discovery rate procedure to correct for multiple comparisons. When doing so, the differences Bilbao vs. Oxford (1) and Bilbao vs. the rest (4) are still significant at the 5\% level.

${ }^{11}$ When we add to the regression analysis the few participants who inverted the distribution and multiply their measure by -1 , the triple interaction effects reported in columns (1) and (4) of Table 3 remain statistically significant.
} 
Norway and the United States, the differences between Bilbao and Córdoba, on the one hand, and Norway and the United States, on the other, are distinct. The notable difference between Bilbao and Córdoba is in the extent to which the less educated tolerate inequality owing to differences in productivity. The notable differences between Norway and the United States are, first, the overall difference in inequality acceptance and, second, the extent to which the highly educated tolerate inequality owing to differences in productivity.

Finally, the graphs for Oxford and Cape Town are very distinct. The critical difference here is that, in both Oxford and Cape Town, the less educated implemented much higher levels of inequality in the luck treatment-levels that were statistically indistinguishable from those that they implemented in the merit treatment.

\section{Summary and discussion}

A large number of observational and experimental studies have explored the determinants of individual preferences for redistribution. In general, inequalities are more likely to be accepted by people of higher socioeconomic status, in richer societies and when inequalities are perceived as jusfifiable owing to differences in productivity. ACT identified a triple interaction between these three variables.

We have replicated ACT's triple interaction effect finding using data from experiments conducted in four locations across three countries all distinct from the ones studied by ACT. However, a closer look at the data indicates that the origin of the triple interaction effect varies depending on which societies one compares. ACT's data for Norway and the United States indicate that meritocratic values among the highly educated are less prevalent in more equal societies and that this is the driver of the triple interaction effect. In contrast, in the Barr et al. $(2015 ; 2016)$ data, the triple interaction effects have multiple drivers. In the comparsion of Bilbao and Cape Town, the principle driver is that the less educated in the relatively unequal society are relatively accepting of inequality even when it is owing to luck. In the comparison of Bilbao and Córdoba the principle driver is that the less educated in the relatively unequal society are less accepting of inequality owing to differences in productivity. And in the comparison of Bilbao and Oxford both of these drivers are present.

Taken together, ACT and the Barr et al. $(2015 ; 2016)$ data indicate that individual education, the level of inequality in a society and the perceived origin of that inequality interact to determine the extent to which inequality is accepted. However, the mechanisms driving the interaction vary depending on which societies we look at and compare. If we are to gain a better understanding of these mechanisms, more work is needed. One interesting issue for future 
research is how to think about the relevant society for such a study, since ACT focuses on country comparisons, while the present study focuses on smaller units (cities).

More generally, this triple interaction effect has potentially far-reaching research and policy implications. With regard to research, it offers a new perspective on the four seemingly separate economic literatures on: human capital; the individual-level determinants of preferences for redistribution; the societal and contextual determinants and moderators of those preferences; and experiments identifying the effects of the source of inequality on inequality acceptance. With regard to policy, ACT's result suggests that in highly equal societies education might not promote meritocratic values. This would be a concern if, as a consequence, investment in education was lower. However, this is not what we observe when we compare Norway and the United States. In the United States adults with tertiary degrees earn $75 \%$ more than those with upper secondary education, while in Norway this earnings gap is just $25 \%$ (OECD, 2017). Yet, despite the lower financial return to education, investment in human capital is slightly higher in Norway (World Bank, 2019). ${ }^{12}$ One possible explanation for this apparent mismatch is that non-financial intrinsic motivations to work and be productive also vary across societies and, in the case of Norway vs. the United States, are inversely related to the returns to education. When we compare the Employment Commitment Index values for Norway and the United States, this is precisely what we observe (Esser, 2009). ${ }^{13}$ Thus, it would seem that investment in human capital and the desire to work are not inextricably linked to the financial returns associated with each and that more egalitarian values and other positive intrinsic motivations could pave the way to greater prosperity without greater inequality. ${ }^{14}$

\footnotetext{
12 The Human Capital Index values for Norway and the United States are 0.77 and 0.76 respectively (World Bank, 2019).

${ }^{13}$ In 2005, the Employment Commitment Index values for men and women in Norway were 3.82 and 3.95 respectively and the Employment Commitment Index value for both men and women in the United States was 3.48 (Esser, 2009).

${ }^{14}$ An alternative hypothesis would be differences in public investment in human capital.
} 
TABLE 1

REGRESSION RESULTS ON IMPLEMENTED INEQUALITY

\begin{tabular}{|c|c|c|c|c|}
\hline & $\begin{array}{c}(1) \\
\text { Bilbao }\end{array}$ & $\begin{array}{c}(2) \\
\text { Córdoba }\end{array}$ & $\begin{array}{c}\text { (3) } \\
\text { Oxford }\end{array}$ & $\begin{array}{c}\text { (4) } \\
\text { Cape Town }\end{array}$ \\
\hline \multicolumn{5}{|l|}{ Panel A } \\
\hline \multirow[t]{2}{*}{ Merit } & $0.071 * *$ & $0.062 * *$ & 0.042 & 0.034 \\
\hline & $(0.024)$ & $(0.012)$ & $(0.024)$ & $(0.025)$ \\
\hline \multirow[t]{2}{*}{ Constant } & -0.066 & 0.037 & 0.021 & 0.057 \\
\hline & $(0.100)$ & $(0.047)$ & $(0.043)$ & $(0.049)$ \\
\hline Observations & 174 & 214 & 110 & 126 \\
\hline Additional controls & Yes & Yes & Yes & Yes \\
\hline \multicolumn{5}{|l|}{ Panel B } \\
\hline \multirow[t]{2}{*}{ Merit } & 0.086 & 0.035 & -0.008 & 0.010 \\
\hline & $(0.065)$ & $(0.020)$ & $(0.035)$ & $(0.030)$ \\
\hline \multirow[t]{2}{*}{ Highly Educated } & 0.009 & 0.000 & -0.063 & -0.067 \\
\hline & $(0.059)$ & $(0.019)$ & $(0.038)$ & $(0.043)$ \\
\hline \multirow[t]{2}{*}{ Merit x Highly Ed } & -0.017 & 0.042 & $0.099 *$ & 0.077 \\
\hline & $(0.070)$ & $(0.025)$ & $(0.049)$ & $(0.056)$ \\
\hline \multirow[t]{2}{*}{ Constant } & -0.073 & -0.001 & 0.037 & 0.058 \\
\hline & $(0.108)$ & $(0.001)$ & $(0.045)$ & $(0.049)$ \\
\hline Observations & 174 & 214 & 110 & 126 \\
\hline Additional controls & Yes & Yes & Yes & Yes \\
\hline
\end{tabular}

Note: Table reports estimated coefficients from regressions for Implemented inequality on the listed explanatory variables plus additional controls - age, female and subjective economic status. Standard errors, clustered at the session level, reported in parentheses. Additional controls are age, female and subjective economic status. Data samples defined in column titles. The table presents eight regressions each focusing on one of the four Barr et al. $(2015$; 2016) research locations. For each society, two regressions are presented. The first (Panel A) takes Implemented inequality as the dependent variable and merit and a set of standard controls as the explanatory variables. The second (Panel B) builds on the first by including highly educated and its interaction with merit as additional regressors. $* *-$ sig. at $1 \% ; *-$ sig. at $5 \%$. 
TABLE 2

HETEROGENEITY ANALYSIS ON IMPLEMENTED INEQUALITY

\begin{tabular}{|c|c|c|c|c|}
\hline & $\begin{array}{c}(1) \\
\text { Oxford } \\
\text { vs } \\
\text { Bilbao }\end{array}$ & $\begin{array}{c}\text { (2) } \\
\text { Córdoba } \\
\text { vs } \\
\text { Bilbao }\end{array}$ & $\begin{array}{c}(3) \\
\text { Cape Town } \\
\text { vs } \\
\text { Bilbao }\end{array}$ & $\begin{array}{l}\text { (4) } \\
\text { Bilbao } \\
\text { vs } \\
\text { others }\end{array}$ \\
\hline \multirow[t]{2}{*}{ Merit } & -0.010 & $0.039 *$ & 0.010 & 0.018 \\
\hline & $(0.027)$ & $(0.018)$ & $(0.029)$ & $(0.016)$ \\
\hline \multirow[t]{2}{*}{ Bilbao } & $-0.048 *$ & -0.009 & $-0.065^{*}$ & $-0.040 * *$ \\
\hline & $(0.021)$ & $(0.014)$ & $(0.032)$ & $(0.015)$ \\
\hline \multirow[t]{2}{*}{ Highly Educated } & $-0.063 *$ & -0.001 & $-0.067 *$ & $-0.039 * *$ \\
\hline & $(0.027)$ & $(0.008)$ & $(0.030)$ & $(0.014)$ \\
\hline \multirow[t]{2}{*}{ Merit x Bilbao } & $0.095 * *$ & 0.052 & 0.075 & $0.071^{*}$ \\
\hline & $(0.034)$ & $(0.032)$ & $(0.038)$ & $(0.029)$ \\
\hline \multirow[t]{2}{*}{ Merit x Highly Ed } & $0.103 * *$ & 0.039 & 0.079 & $0.065 * *$ \\
\hline & $(0.037)$ & $(0.021)$ & $(0.043)$ & $(0.019)$ \\
\hline \multirow[t]{2}{*}{ Bilbao x Highly Ed } & $0.070 * *$ & 0.021 & $0.077 *$ & $0.054 * *$ \\
\hline & $(0.023)$ & $(0.013)$ & $(0.033)$ & $(0.017)$ \\
\hline \multirow[t]{2}{*}{ Merit x Bilbao x Highly Ed } & $-0.120^{*}$ & -0.064 & -0.098 & $-0.087 *$ \\
\hline & $(0.045)$ & $(0.038)$ & $(0.053)$ & $(0.036)$ \\
\hline \multirow[t]{2}{*}{ Constant } & 0.029 & 0.014 & 0.048 & 0.025 \\
\hline & $(0.031)$ & $(0.010)$ & $(0.049)$ & $(0.021)$ \\
\hline Observations & 284 & 388 & 300 & 524 \\
\hline Additional controls & Yes & Yes & Yes & Yes \\
\hline \multicolumn{5}{|l|}{ lincom: } \\
\hline \multirow[t]{2}{*}{ Merit (not Bilbao, Highly Ed) } & $0.093 * *$ & $0.077 * *$ & $0.089 * *$ & $0.082 * *$ \\
\hline & $(0.017)$ & $(0.012)$ & $(0.038)$ & $(0.011)$ \\
\hline \multirow[t]{2}{*}{ Merit (Bilbao, Less Ed) } & $0.085 * *$ & $0.090 * *$ & $0.085 * *$ & $0.088 * *$ \\
\hline & $(0.025)$ & $(0.026)$ & $(0.026)$ & $(0.024)$ \\
\hline \multirow[t]{2}{*}{ Merit (Bilbao, Highly Ed) } & $0.067 * *$ & $0.065 * *$ & $0.066^{* *}$ & $0.066 * *$ \\
\hline & $(0.019)$ & $(0.018)$ & $(0.019)$ & $(0.019)$ \\
\hline
\end{tabular}

Note: Table reports estimated coefficients from regressions for Implemented inequality similar in specification to that in column 2 of Table 4 in ACT. Additional controls: age, female and subjective economic status. Data samples defined in column titles. Standard errors, clustered at the session level, reported in parentheses. The table presents four regressions taking Implemented inequality as the dependent variable and using a model specification similar to that used by ACT in the middle column of their Table $4 . * *-$ sig. at $1 \%$; *- sig. at $5 \%$. 


\section{References}

Alesina, A. and Giuliano, P. (2011). 'Preferences for redistribution.' In Handbook of Social Economics, eds. J. Benhabib, A. Bisin and M. O. Jackson. North Holland: Elsevier, 93-132. Almås, I., Cappelen, A. W. and Tungodden, B. (2019). 'Cutthroat Capitalism versus Cuddly Socialism: Are Americans More Meritocratic and Efficiency-seeking than Scandinavians?', Journal of Political Economy, forthcoming.

Barr, A., Burns, J., Miller, L. and Shaw, I. (2015). 'Economic status and acknowledgement of earned entitlement', Journal of Economic Behavior and Organization, vol. 118, pp. 55-68.

Barr, A., Miller, L. and Ubeda, P. (2016). 'Moral consequences of becoming unemployed', Proceedings of the National Academy of Sciences of the United States of America, vol. 113(17), pp. 4676-4681.

Cappelen, A.W., Moene, K. O., Sorensen, E. O. and Tungodden, B. (2013). 'Needs vs entitlements - an international fairness experiment', Journal of the European Economic Association, vol. 11, pp. 574-598.

Castillo, J. C. (2011). The Legitimacy of Economic Inequality: An Empirical Approach to the Case of Chile. Boca Raton, FL: Dissertation.com.

Demel, S., Barr, A., Miller, L. and Ubeda, P. (2018). 'Commitment to Political Ideology is a Luxury Only Students Can Afford: A Distributive Justice Experiment', Journal of Experimental Political Science, vol. 6(1), pp. 33-42.

Cherry, T.L., Frykblom, P., and Shogren, J. F. (2002). 'Hardnose the dictator', American Economic Review, vol. 92 (4), pp. 1218-1221.

Esser, I. (2009). 'Has Welfare Made Us Lazy? Employment Commitment in Different Welfare States.' In British Social Attitudes: The 25th Report, A. Park, J. Curtice, K. Thomson, M. Phillips and E. Clery (eds.), New York: SAGE Publications Ltd.

Fernandez J. J. and Jaime-Castillo, A. M. (2018). 'The Institutional Foundation of Social Class Differences in Pro-redistribution Attitudes: A Cross-National Analysis, 1985-2010', Social Forces 96(3): 1009-1038.

Frohlich, N., Oppenheimer, J. and Kurki, A. (2004). 'Modeling other-regarding preferences and an experimental test', Public Choice, vol. 119, pp. 91-117.

Jakiela, P., Miguel, E. and te Velde, V. (2014). 'You've earned it: estimating the impact of human capital on social preferences.' Experimental Economics, vol. 18(3), pp. 385-407.

Jakiela, P. (2015). 'How fair shares compare: Experimental evidence from two cultures', Journal of Economic Behavior and Organization, vol. 118, pp. 40-54. 
Konow, J., (2000). 'Fair shares: accountability and cognitive dissonance in allocation decisions', American Economic Review, vol. 90 (4), pp. 1072-1091.

Konow, J., (2005). 'Blind spots: The effects of information and stakes on fairness bias and dispersion', Social Justice Research, vol. 18 (4), pp. 349-390.

Margalit, Y. (2013). 'Explaining social policy preferences: Evidence from the Great Recession', American Political Science Review, vol. 107(1), pp. 80-103.

Margalit, Y. (2019). 'Political Responses to Economic Shocks', Annual Review of Political Science, vol. 22, pp. 277-295.

OECD. (2017). Education at a Glance 2017: OECD Indicators. OECD Publishing: Paris.

Owens, L. A., and Pedulla, D. S. (2014). 'Material welfare and changing political preferences: The case of support for redistributive social policies'. Social Forces, vol. 92(3), pp. 10871113.

Sands, M. L. (2017). 'Exposure to inequality affects support for redistribution', Proceedings of the National Academy of Sciences of the United States of America, vol. 114, pp. 663-668.

World Bank. (2019). World Development Report 2019: The Changing Nature of Work. Washington, DC: World Bank. 